\title{
Origination, extinction, and mass depletions of marine diversity
}

\author{
Richard K. Bambach, Andrew H. Knoll, and Steve C. Wang
}

\begin{abstract}
In post-Cambrian time, five events-the end-Ordovician, end-Frasnian in the Late Devonian, end-Permian, end-Triassic, and end-Cretaceous-are commonly grouped as the "big five" global intervals of mass extinction. Plotted by magnitude, extinction intensities for all Phanerozoic substages show a continuous distribution, with the five traditionally recognized mass extinctions located in the upper tail. Plotted by time, however, proportional extinctions clearly divide the Phanerozoic Eon into six stratigraphically coherent intervals of alternating high and low extinction intensity. These stratigraphic neighborhoods provide a temporal context for evaluating the intensity of extinction during the "big five" events. Compared with other stages and substages in the same neighborhood, only the end-Ordovician, end-Permian, and end-Cretaceous extinction intensities appear as outliers. Moreover, when origination and extinction are considered together, only these three of the "big five" events appear to have been generated exclusively by elevated extinction. Low origination contributed more than high extinction to the marked loss of diversity in the late Frasnian and at the end of the Triassic. Therefore, whereas the "big five" events are clearly times when diversity suffered mass depletion, only those at the end of the Ordovician, Permian, and Cretaceous periods unequivocally qualify as globally distinct mass extinctions. Each of the three has a unique pattern of extinction, and the diversity dynamics of these events differ, as well, from the other two major diversity depletions. As mass depletions of diversity have no common effect, common causation seems unlikely.
\end{abstract}

Richard K. Bambach and Andrew H. Knoll. Botanical Museum, Harvard University, 26 Oxford Street, Cambridge, Massachusetts 02138. E-mail: rbambach@oeb.harvard.edu

Steve C. Wang. Department of Mathematics and Statistics, Swarthmore College, 500 College Avenue,

Swarthmore, Pennsylvania 19081. E-mail: scwang@swarthmore.edu

Accepted: 15 February 2004

\section{Introduction: \\ Mass versus "Background" Extinction}

The idea that mass extinctions stand out as a class of events separate from the range of "normal" or "background" extinctions that characterize most of the geological record originated with the work of Norman Newell (1962, 1963, 1967) and crystallized through the quantitative analysis by Raup and Sepkoski (1982). Using Sepkoski's compilation of stratigraphic ranges temporally resolved to the stage level for marine families of all animal taxa (Sepkoski 1982), Raup and Sepkoski identified five mass extinctions: the end-Ordovician (Ashgillian); Late Devonian (including the Frasnian/Famennian boundary); endPermian (Guadalupian and Djhulfian together); end-Triassic (Late Norian or Rhaetian); and end-Cretaceous (Maastrichtian). These have become known informally as "the big

\footnotetext{
* This paper is dedicated to the memory of Stephen Jay Gould (1941-2002).
}

five" mass extinctions. Each had been noted earlier by Newell (1967).

Raup and Sepkoski plotted the extinction rate (number of families going extinct per million years) for each stage in time order and assumed that apparent outliers on the arithmetic plot were true statistical outliers (and not aberrations produced by errors in the timescale), thus identifying a distinct class of mass extinctions. They also calculated a 95\% confidence interval around the remaining "background" extinction stages and demonstrated a secular decrease in extinction rates over time. Quinn (1983), however, showed that the extinction data were highly skewed and correctly pointed out that the assumption of a normal distribution for "background" extinction data was not valid. When log-transformed, the distribution of extinction rates was approximately normal and did not have a suite of outliers that could be categorized unambiguously as a class of mass extinctions separate from the overall "background" distribution. Bambach and Gilinsky (1986) dem- 
onstrated that this was also the case for several other extinction metrics, including proportional metrics by interval that are not subject to time-scale error. For all metrics the distribution of extinction intensity grades smoothly from lowest to highest values with no discrete break between "background" and presumed mass extinction intervals. Indeed, Raup (1991) developed his view of the Phanerozoic kill curve on the basis of this continuity of extinction magnitudes. Bambach and Gilinsky (1986) did, however, support the finding that extinction intensities (and origination intensities, as well) declined during the Phanerozoic, a conclusion discussed more fully by Gilinsky (1994).

Despite the evidence that intensities of extinction form a continuum, the five events specified by Raup and Sepkoski (1982) continue to be labeled "mass extinctions" (Finney et al. 1999; McGhee 2001; Wignall and Twitchett 1996; Pálfy et al. 2000; MacLeod and Keller 1996). Current threats to biodiversity have even been labeled "the sixth extinction" (Leakey and Lewin 1995). It may be that magnitude alone is sufficient to justify the term "mass extinction" because events with such pronounced loss of diversity are rare, with waiting times of about 100 million years (Raup 1991). But is there any reason to think of these events as a separate class of events, rather than as the uncommon upper tail of a continuous distribution?

Wang (2003) recently identified three concepts that must be considered individually when we ask whether putative mass extinctions grade continuously into the range of background extinction: continuity of cause, continuity of effect, and continuity of magnitude. Continuity of cause would be demonstrated if candidate mass extinctions could be shown to be driven by the same processes that are responsible for background extinction, albeit operating at increased intensity or over larger areas. Continuity of effect would be established if background and mass extinctions exhibited common patterns of selectivity on taxonomic, functional, ecological, or other grounds. And continuity of magnitude would exist if the distribution of intensities of mass extinctions graded smoothly and continuous- ly into intensities of background extinction. Although continuity of magnitude appears to have been demonstrated by Quinn (1983) and Bambach and Gilinsky (1986), and was assumed by Raup (1991) in his kill curve analysis for the Phanerozoic, several factors led us to reconsider the status of these intervals. These include (a) the rarity of the largest extinction intensities, (b) the possibility that they do not share continuity of cause or effect with all other intervals, and (c) the fact that origination and extinction have rarely been considered together in examining patterns of diversity change.

In the following sections, we reevaluate the continuity or discontinuity of magnitude and then briefly consider whether events that might be regarded as mass extinctions can be unified by effect or cause. We test whether any of the "big five" events are differentiable from the distribution of other extinction intensities, explore the role of origination as well as extinction in diversity changes associated with these five intervals, and comment on the differences, as well as similarities, among the intervals. The upshot will be that although the five intervals in question-the end-Ordovician, Late Devonian, end-Permian, end-Triassic, and end-Cretaceous-are the five intervals with the greatest diversity loss in the Phanerozoic, they share little else in common. Only three were driven predominantly by extinction and even they display distinctly different patterns of diversity change, implying that these events are not related by continuity of effect or cause.

\section{Tracking Genus Diversity}

Figure 1 illustrates the history of marine genus diversity through Phanerozoic time. The data were compiled by using a computerized sorting routine written by Jack Sepkoski and modified by J. Bret Bennington to tabulate genus diversity for 107 stages and substages using Jack Sepkoski's unpublished tabulation of the stratigraphic ranges of genera as of 1996 . Although the Paleontological Research Institution has recently published the raw genus ranges from a later version (1998) of Sepkoski's compilation (Sepkoski 2002), this publi- 


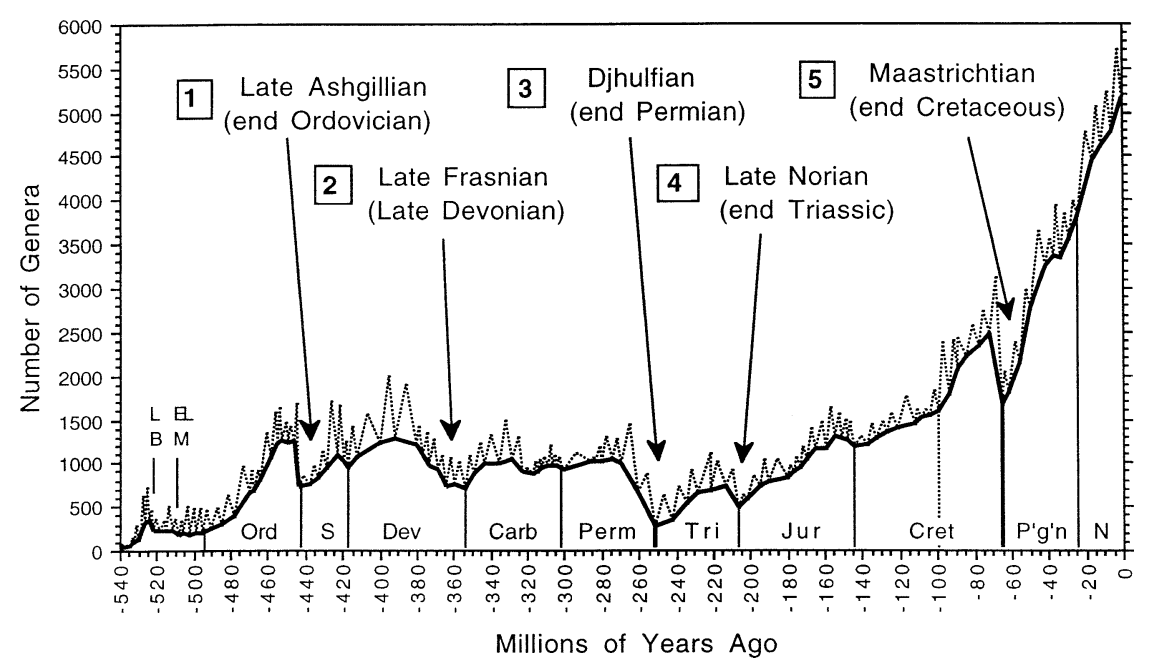

FIGURE 1. Diversity and diversity turnover of marine genera by interval through the Phanerozoic. The five major post-Cambrian diversity depletions are highlighted. The heavy line connects the data on number of genera crossing each interval boundary. The line directly connecting the numbers of boundary-crossing genera follows the path of minimum likely standing diversity, regarded as the minimum diversity because origination and extinction would have to work in exact lock-step to follow that diversity path. The peaked dotted line represents genus turnover within each interval. The rising part of each peak represents all genus originations (first occurrences) reported from the interval. The peak records the total number of genera reported from the time interval. The descending part of the peak represents the number of extinctions (last records) of genera in the interval. The magnitudes of the peaks compared with the minimum standing diversity at interval boundaries represent the degree of faunal turnover in the intervals.

cation simply lists all the genera and does not numerically tabulate the data on diversity.

Genus diversity follows the general pattern established in the "consensus paper" of Sepkoski et al. (1981) and best known from Sepkoski's (1981: Fig. 5) widely reproduced family diversity curve. In the Paleozoic we see the "Cambrian Explosion" (the increase in diversity in the Early Cambrian), a Middle and Late Cambrian "plateau" of diversity, and the Ordovician Radiation, followed by the long interval of fluctuating, but non-trending, diversity that began in the Caradocian and lasted for the rest of the era. Diversity changes during this "Paleozoic Plateau" include three of the "big five" diversity depletions, the endOrdovician, the Late Devonian, and the endPermian events. The post-Paleozoic is characterized by nearly continuous diversity increase, interrupted by the other two "big five" diversity depletions, the end-Triassic and the sharp, era-bounding end-Cretaceous events. Note that because we tabulated subgenera of mollusks, resolved the data to the substage level, and emphasized the diversity at interval boundaries rather than the total diversity within each interval, the apparent Cenozoic increase in diversity is proportionately greater than that illustrated by Sepkoski for families.

There are some concerns that the apparently large Cenozoic increase in diversity may be partly artifactual. However, recent analyses (Bush and Bambach in press on alpha diversity; Jablonski et al. 2003 on Pull of the Recent; and Bush et al. 2001, in press on techniques of sample-standardization) demonstrate that an increase in Cenozoic diversity is strongly indicated, although the exact amount is still unclear (Jackson and Johnson 2001). The "consensus paper" (Sepkoski et al. 1981) was put together because several of the data sets avoided or mitigated some of the biases, such as imperfections of the geologic record, that were of concern then and still are (Peters and Foote 2001). Although every potential problem should be analyzed and improvement in the data is necessary, it still appears, as was concluded then, that the diversity signal is stronger than the noise.

Figure 1 accounts for all the data in the Sepkoski genus compilation (see caption for full explanation). Many diversity curves use total 
diversity as the recorded data (this is true for published illustrations of Sepkoski's family curve, for example). If one mentally "connects the dots" of total diversity peaks in Figure 1, it is clear that the general shape of a curve connecting total diversities would be very similar to the boundary-crossing diversity emphasized here. Mid-Devonian diversity would appear higher than Late Ordovician diversity, Carboniferous diversity would fluctuate more, and the upturn in diversity in the mid-Cretaceous would be sharper than shown by the standing diversity plot. The general pattern, however, would be the same.

We use the boundary-crossing standing diversity as the preferred representation of diversity and diversity change through time. We know that boundary-crossing diversity is not anomalous compared with total diversity because the trend of boundary-crossing diversity follows the general path of total diversity. Two factors make us prefer it to total diversity. First, it is the only measure we have of actual standing diversity. Total diversity in an interval was not the actual standing diversity at any time because it is unlikely that all originations occurred in an interval before any extinction. However, the recorded diversity at the boundaries of each interval, calculated by subtracting all extinctions in the interval from the total diversity in the interval, is a direct measure of standing diversity at interval boundaries. The other compelling reason is that change in diversity is shown best by comparing diversity at the start of different intervals.

Diversity is a function of both origination and extinction. The peaks of turnover within each interval in Figure 1 reveal how much variation of diversity can occur in any interval, but comparing standing diversities at interval boundaries tells us whether origination and extinction are in balance (little or no change of diversity from one boundary to the next) or whether either origination or extinction dominated during an interval (origination dominating if boundary-crossing diversity increases, extinction being more important if boundary-crossing diversity decreases). In plots of total diversity, a predominance of extinction over origination in one interval could be masked by an increase in origination in the next. Total diversity might appear unchanged between the two intervals because origination in a rapid recovery from an extinction event could make total diversity in the succeeding interval equal to that in the previous one, concealing the low diversity at the start of the interval. For example, although extinction exceeded origination in each of the last two intervals of the Silurian and diversity appears to have been lost between the Ludlovian and Pridolian when looking at total diversity, the low point of diversity at the end of the Silurian (end-Pridolian) is masked in the total diversity curve because, in the Gedinnian, the first interval of the Devonian, origination was high, causing total diversity to exceed that of the Pridolian. Boundary-crossing diversity not only approximates standing diversity, but it also gives a clearer representation of the consequences of within-interval evolutionary dynamics than that provided by summed total diversity data for whole intervals.

\section{The "Big Five" as Diversity Depletions}

Inspection of Figure 1 reveals that, although diversity decreased slightly on several other occasions, there are only five post-Cambrian intervals when diversity decreased markedly: (1) at the end of the Ordovician, (2) during the Middle and Late Devonian, (3) during the Late Permian, (4) at the end of the Triassic, and (5) at the end of the Cretaceous. The end-Triassic decrease does not look as large as the other four, but standing diversity throughout the Triassic was lower than at any other time after the mid-Ordovician, so the proportional decrease in the latest Triassic is quite comparable to the other four major diversity depletions. Two Cambrian intervals are also noted on Figure 1 (the late Botomian [LB] and early late Middle Cambrian [ELM]). These were times of relatively small numerical change in diversity but high proportional diversity loss. Because the evolutionary dynamics of the Cambrian and Early Ordovician are unusual we will consider them separately; the bulk of this paper emphasizes the post-Arenig portion of the Phanerozoic.

Because it is hard to judge the proportional magnitude of diversity change from a plot of 


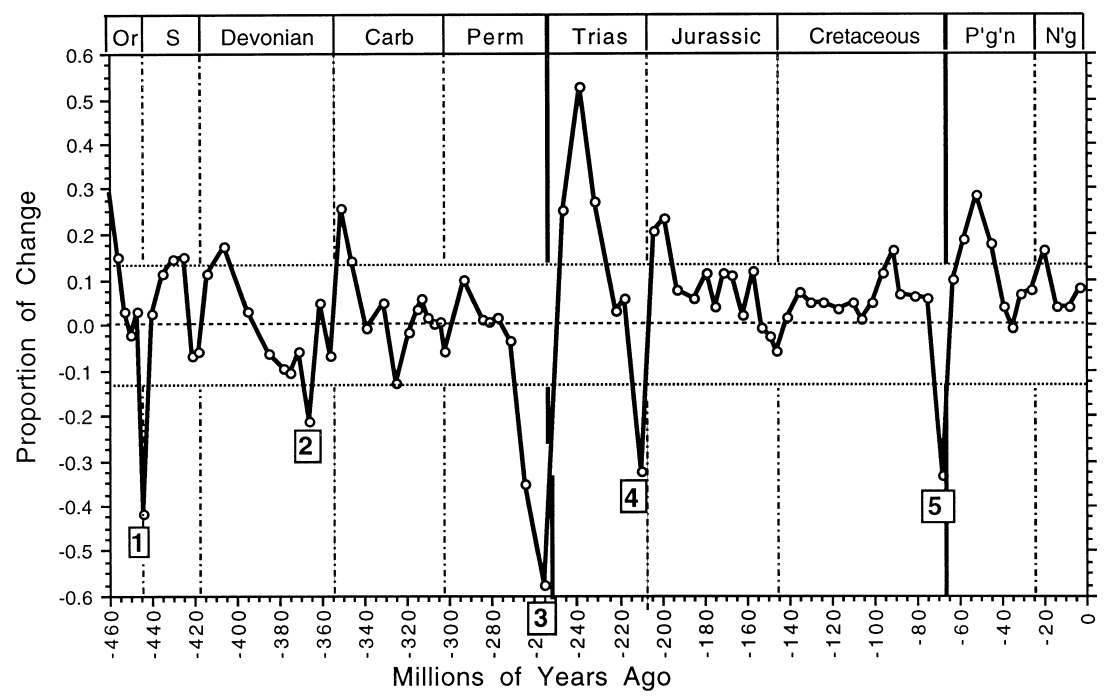

FIGURE 2. Proportion of gain or loss of genus diversity from the Caradoc to the Plio-Pleistocene. The five major diversity depletions (decrease greater than 20\%) are numbered. Symmetrical lines are drawn at $-13.5 \%$ and $+13.5 \%$ (based on the sixth largest diversity decrease) to indicate the range that might be regarded as "background" fluctuation in diversity. Intervals with greater than $13.5 \%$ diversity increase are common only after major diversity depletions.

absolute values, a plot of proportion of gain or loss of diversity, rather than a plot of the numbers of genera as such, is desirable. A display of numbers of taxa, as in Figure 1, is useful for illustrating the pattern of change in diversity, but the numbers represent only those taxa discovered in the fossil record and are not a complete record of all the taxa that existed. Proportional diversity change is what we seek to understand here-how episodes of diversity loss affected the whole biota. The question, in effect, concerns the importance of an event in the context of its time, not just how many taxa were involved.

Figure 2 shows the proportional gain or loss in the number of genera during each stage or substage interval, starting with the Early Caradocian in the Middle Ordovician after the large proportional increases in diversity associated with the Cambrian Explosion and the Ordovician Radiation were over. The change in diversity is calculated as a proportional change by subtracting the number of genera at the start of each interval (the standing diversity at the boundary between the interval and its preceding interval) from the number of genera at the end of the interval (the standing diversity at the boundary between the interval and its succeeding interval) and dividing that number (the change in the number of genera from the start to the end of the interval) by the number of genera at the start of the interval. For example, if 500 genera pass from interval one to interval two and 600 genera pass from interval two to interval three, then there were 100 more originations than extinctions during interval two, with a gain in diversity of 100 genera, a proportional increase of +0.200 . Likewise, a decrease from 600 to 500 genera during an interval (a loss of 100 genera as a result of 100 more extinctions than originations) would be a proportional decrease of -0.167 . As noted above, an advantage of determining standing diversity at interval boundaries is that one can follow the balance of origination and extinction as it influences diversity change, something not possible when only tabulating total diversity for each interval.

Figure 2 shows that the five intervals already well known as the classic "big five" mass extinctions (with the Guadalupian as well as the end-Permian Djhulfian included in the major later Permian diversity decrease [Stanley and Yang 1994]) are the only postLlandeilian intervals with more than a $20 \%$ proportional loss of genus diversity. In fact, there is a gap of $8 \%$ between the largest loss 
of diversity not included in the "big five" and the smallest loss within the "big five," but no gaps of as much as $2 \%$ occur between any smaller values when arranged in rank order. These five intervals were certainly times of mass depletion of diversity, but can we justify regarding any of them as times of mass extinction different in cause, effect, or magnitude from "background" extinction?

\section{Large-Magnitude Proportional Increases in Diversity}

As a side issue, but one related to proportional diversity change and its timing, it is interesting to note that the only times when proportional increase of diversity exceeds $13.5 \%$ are during the Cambrian Explosion, the Ordovician Radiation (just ending in the early Caradocian at the start of Fig. 2), in the immediate aftermath of each of the five "mass depletions" of diversity, and briefly (single intervals only) in the Late Cretaceous (Turonian) and Neogene (early Miocene) (Fig. 2). Although origination rates are not unusually high in these intervals (no outliers for origination are found in an analysis of origination proportions at these times), the combination of higher origination and lower extinction during the "recovery" phase after diversity depletion does mark these intervals as times of unusually great proportional increase in diversity. These are not necessarily times of broad transgression or otherwise better representation of the marine record, so higher origination rates in the wake of major diversity depletions may reflect recovery from unusually low diversity and not just the effect of improved record availability, a possibility raised by Peters and Foote (2001).

\section{Testing for Continuity of Magnitude of Extinction}

We tested for continuity or discontinuity of magnitude of extinction (i.e., whether or not the distribution of intensities of apparent mass extinctions grade smoothly and continuously into intensities of background extinction) in two ways. (1) We tested whether there is a smooth continuous distribution of magnitudes of extinction intensity with no strong variation in the upper tail of the distribution, first for the whole Phanerozoic and second for the time after the after the "Cambrian Plateau" of low diversity and high turnover. (2) We compared magnitudes of extinction for each interval against the distribution of magnitudes of extinction in the particular segment of the timescale, based on average high or low extinction rates, to which the interval belongs. Only if an interval satisfies both criteria, that is, if the interval is not part of a continuous smooth distribution of magnitudes, and if the interval also appears as an "outlier" in magnitude compared with the other intervals in its particular segment of the timescale, do we regard it as a "true" global mass extinction, different in magnitude from the bulk of associated stratigraphic intervals.

How Continuous Are the Values of Extinction Intensity?-As noted above, several analyses have concluded that the distribution of extinction intensities is apparently continuous (Quinn 1983, Bambach and Gilinsky 1986, Raup 1991, Wang 2003). Figure 3A shows this effect for proportion of genus extinction arranged in rank order for the 107 stages and substages of the Phanerozoic as tabulated in our version of Sepkoski's genus database.

Cambrian and Early Ordovician extinction proportions, however, were consistently high (Table 1, Fig. 4). Sixteen of 19 Cambrian and Early Ordovician intervals have extinction intensities that fall within the top quartile of all Phanerozoic intervals (Fig. 3A). Origination was unusually high, as well, during this interval. Thus, whereas taxonomic turnover at the genus level was great, overall diversity did not fluctuate wildly (Fig. 1 and discussion below). These turnover rates are not like those of much of the later Phanerozoic. For example, the decrease in proportion of extinction observed in the Early Ordovician (Fig. 4A) was not produced by the radiation of taxa with lower extinction rates diluting continuing high extinction rates in the trilobites, which dominated Cambrian diversity. Instead, extinction proportions for trilobites, which had consistently exceeded those of the non-trilobite fauna from the origin of the clade in the early Atdabanian though the early Arenigian (Foote 1988), dropped to the same level as non-trilobite proportions of extinction during 

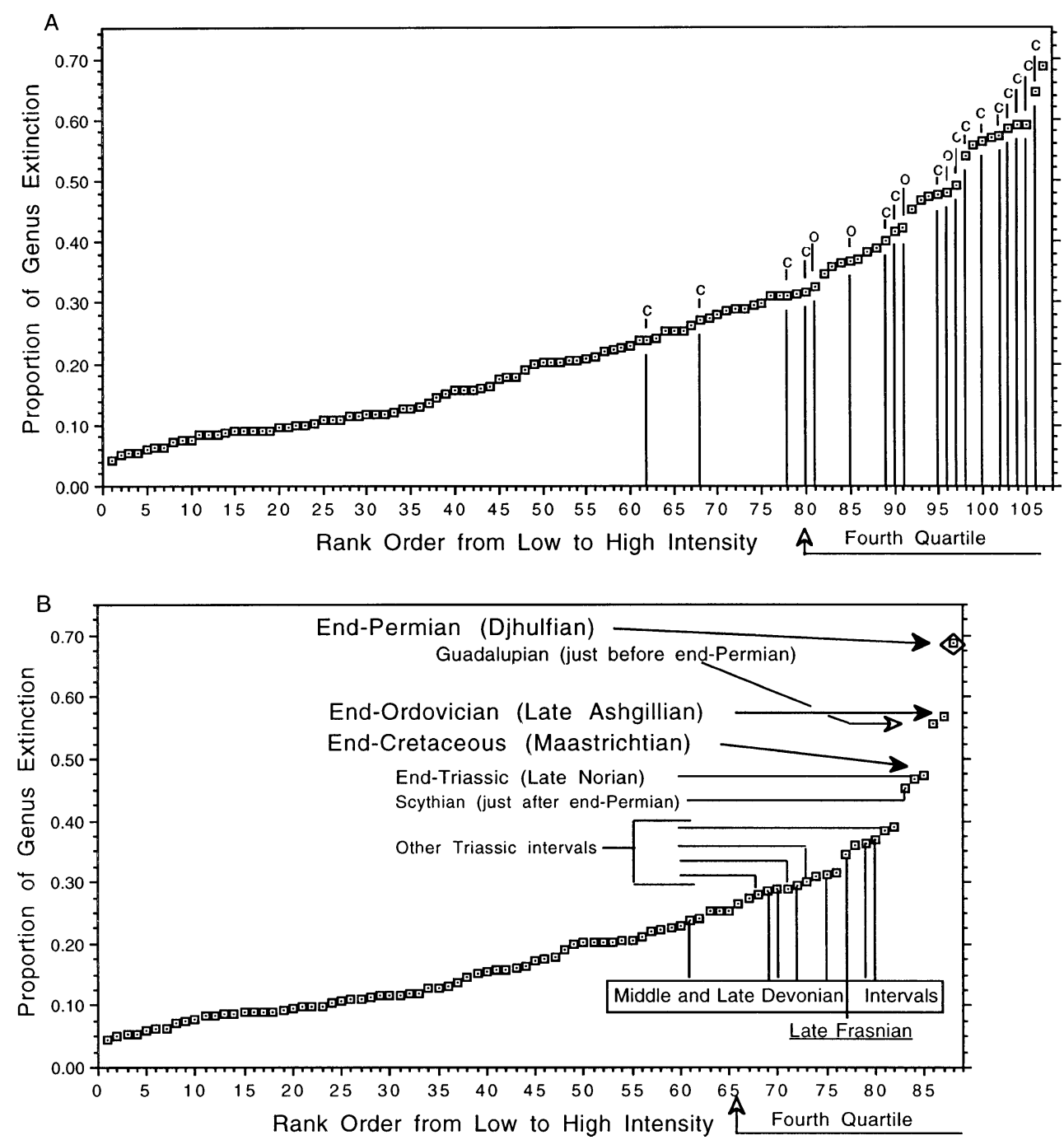

FIGURE 3. Proportions of genus extinction arranged in rank order by magnitude. A, All 107 intervals of the Phanerozoic. Magnitudes from the Cambrian and Early Ordovician are highlighted. B, Middle Ordovician to Plio-Pleistocene values only. Higher magnitude intervals are labeled.

the Late Arenigian and remained at comparable levels thereafter (Fig. 4C). Clearly something changed for trilobite evolutionary dynamics in the later part of the Early Ordovician. Although the change was not as dramatic for the non-trilobite fauna, extinction proportions for that fraction of the fauna, which had been over $30 \%$ in two-thirds of the intervals of the Cambrian and Early Ordovician, dropped to levels below 30\% and remained low until the Middle Silurian, except for the end-Ordovician late Ashgillian extinction event. Proportions of extinction never returned consistently to the high levels common in the Cam- brian and Early Ordovician, even when proportions of extinction increased for extended intervals, such as from the Middle Silurian to the mid-Carboniferous-this held for trilobites and non-trilobites alike.

We do not yet understand why turnover rates should have been so high during the Cambrian and Early Ordovician. Perhaps early animals were more vulnerable to extinction for functional reasons-many Cambrian animals belonged to stem rather than crown groups of bilaterian phyla and classes (Budd and Jensen 2000). Perhaps the low diversity of Cambrian and Early Ordovician animals con- 

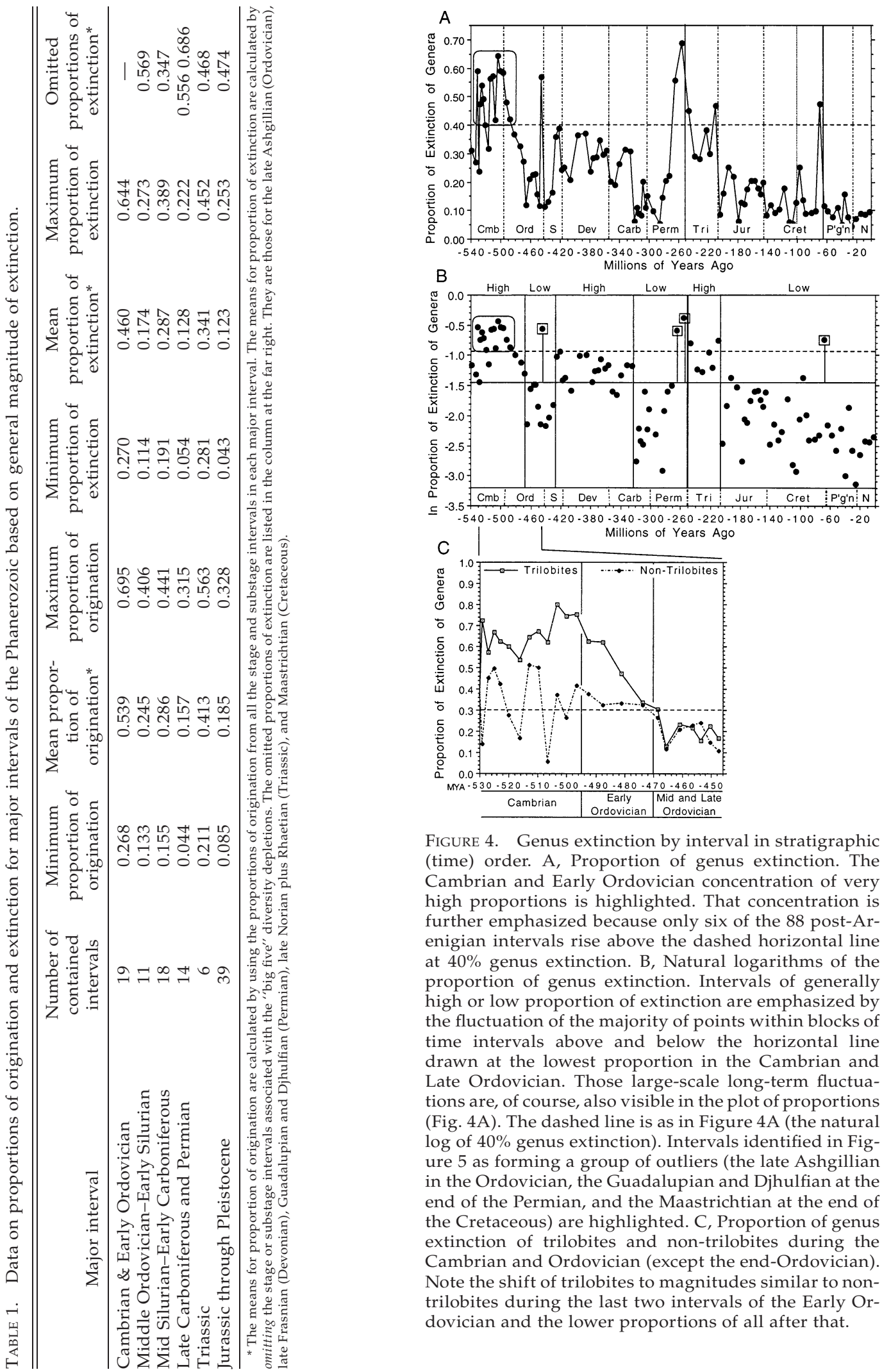

FIGURE 4. Genus extinction by interval in stratigraphic (time) order. A, Proportion of genus extinction. The Cambrian and Early Ordovician concentration of very high proportions is highlighted. That concentration is further emphasized because only six of the 88 post-Arenigian intervals rise above the dashed horizontal line at $40 \%$ genus extinction. B, Natural logarithms of the proportion of genus extinction. Intervals of generally high or low proportion of extinction are emphasized by the fluctuation of the majority of points within blocks of time intervals above and below the horizontal line drawn at the lowest proportion in the Cambrian and Late Ordovician. Those large-scale long-term fluctuations are, of course, also visible in the plot of proportions (Fig. 4A). The dashed line is as in Figure 4A (the natural $\log$ of $40 \%$ genus extinction). Intervals identified in Figure 5 as forming a group of outliers (the late Ashgillian in the Ordovician, the Guadalupian and Djhulfian at the end of the Permian, and the Maastrichtian at the end of the Cretaceous) are highlighted. C, Proportion of genus extinction of trilobites and non-trilobites during the Cambrian and Ordovician (except the end-Ordovician). Note the shift of trilobites to magnitudes similar to nontrilobites during the last two intervals of the Early Ordovician and the lower proportions of all after that. 
tributed to low ecosystem stability (Bambach et al. 2002); many modes of life now heavily occupied were either vacant or contained few taxa (Bambach 1983, 1985). Or perhaps physical environments experienced unusual perturbation during this interval, as might be inferred from the carbon isotope record (Brasier and Sukhov 1998; Saltzman et al. 2000).

Whether we know the cause or not, the observed patterns of turnover show that Cambrian and Early Ordovician extinction rates form a distinct stratigraphic grouping that differs from the remainder of the Phanerozoic Eon. Statistically, it is extremely unlikely that the proportion of extinction in as many as 16 of the 19 Cambrian and Early Ordovician intervals would fall within the top quartile of all Phanerozoic values if there were nothing unusual about that segment of time $(p=$ 0.000000002 , calculated by using the hypergeometric distribution). Thus, we removed these data and replotted the distribution of extinction intensities.

The resulting rank order distribution of mid-Ordovician to Recent extinction intensities (Fig. 3B) retains the original smoothly continuous appearance except for six intervals at the upper end: four of the "big five" (the end-Ordovician, end-Permian, end-Triassic, and end-Cretaceous) and the two intervals that bracket the terminal Permian interval. The high Guadalupian intensity just before the end-Permian Djhulfian likely combines true extinction (Stanley and Yang 1994; Jin et al. 2000) with Signor-Lipps range truncations (Signor and Lipps 1982; Jablonski 1986; Raup 1987) from the exceptionally severe end-Permian event. The initial Triassic interval (the Induan) was a time of low diversity following the end-Permian devastation, and the cause of its high extinction intensity has yet to be determined.

The distribution of extinction intensities for the post-Arenig (Fig. 3B) still can be regarded as a continuous distribution, but one that is more skewed than that for the entire Phanerozoic-the coefficient of skewness for the total Phanerozoic was 0.89 whereas that for the post-Arenig is 1.37. However, it is extremely unlikely that removing 19 randomly selected intervals (consecutive or non-consecutive) would increase the coefficient of skewness to such an extent ( $p<0.0001$, calculated by simulation). The sparseness of the remaining high values raises the question of whether those magnitudes are actually outliers that can be regarded as a separate group from the bulk of lower values.

Do All Intervals That Appear Discontinuous with the Bulk of Post-Arenig Intervals Form a Group of Outliers When Compared with Their "Local" Segment of Geologic Time? -We can test directly for the continuity of magnitude between background and potential mass extinctions in a temporal context. Because the focus of this paper is on the "big five" mass depletions, which are all post-Arenig in age and because the Cambrian and Early Ordovician are not comparable in evolutionary dynamics (for whatever reason, as noted above), we restricted the following analysis to the post-Arenig portion of the Phanerozoic.

We tested for continuity of magnitude between background and mass extinctions over the 88 post-Arenig intervals. To control for the fluctuation in local extinction regimes apparent in the grouping of intervals in Table 1 (for which the boundaries were chosen where the change in extinction proportions seen in Fig. 4 were greatest) we used time-adjusted data rather than the raw extinction intensities. To do this, we first fit a smooth lowess curve to the raw extinction intensities (Fig. 5A). Lowess ("Locally Weighted Scatterplot Smoother" [Cleveland 1979]) is a nonlinear regression method that smoothes out the noise in a time series or scatterplot in order to emphasize the signal. To use lowess, one must first choose the value of a "bandwidth" parameter controlling the degree of smoothing. We used a bandwidth of $11 \%$, meaning that the smoothed value for each interval is calculated as a weighted average of $11 \%$ of the surrounding intervals, with the intervals closest in time weighted more heavily. We chose this value because the average length of a geologic time period in the 470 million years after the Arenig is 52 million years, and $11 \%$ of 470 million is 52 million. Thus the smoothed value for each interval takes into account the extinction intensities of the surrounding intervals for a time equivalent to a geological period. 

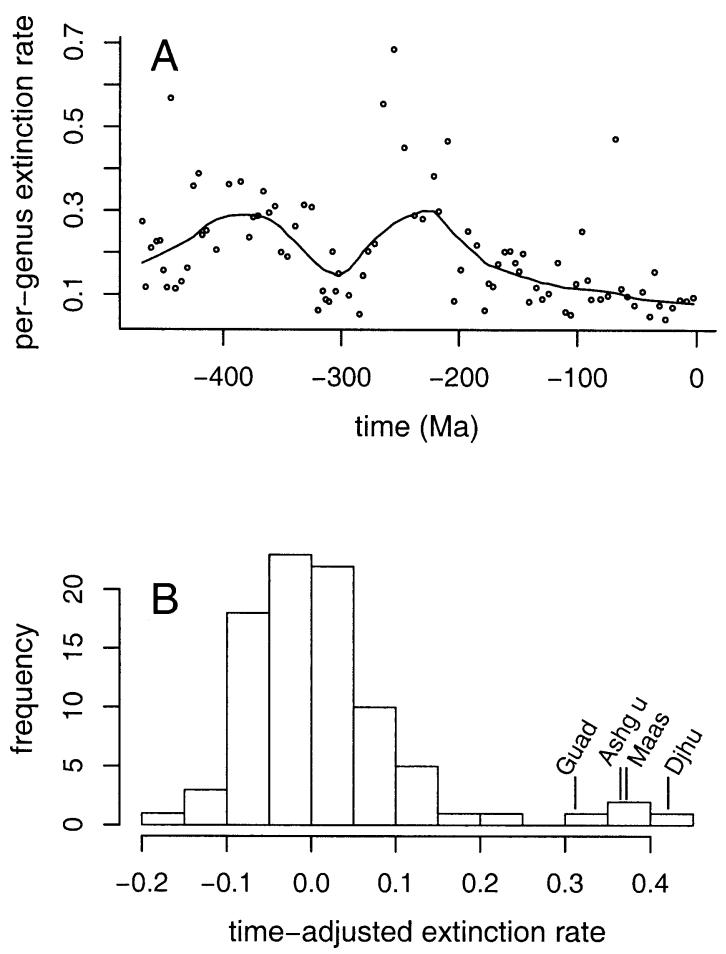

FIGURE 5. Statistical analysis of post-Arenig extinction magnitudes. A, Nonlinear lowess regression with $11 \%$ (52-million-year) bandwidth, revealing long-term fluctuation in extinction intensities. B, Histogram of residuals from nonlinear lowess regression with intervals having intensities comprising a statistically significant second mode $(p=0.028)$ identified. The Induan and the upper Norian are the last two intervals at high end tail of the main mode (time-adjusted values of 0.168 and $0.204)$, but they still lie well below the range of the second mode (0.307-0.416). The late Frasnian time-adjusted value of 0.062 is only the twelfth highest in the main mode and is one of ten values in the second bin above the mode.

We then calculated the residuals, the difference between each interval's extinction intensity and its lowess smoothed value. Using these residuals, we applied the critical bandwidth test (Silverman 1981), previously used by Wang (2003) to test for continuity of magnitude over the entire Phanerozoic. The idea of this test, in this context, is as follows: Suppose there is a curve (i.e., a probability density function) that models an underlying process from which extinction intensities are generated. If this extinction intensity curve were unimodal, we would infer that mass extinctions are the right tail of a continuum of extinction intensities-that background and mass extinctions are continuous in magnitude.
On the other hand, a bimodal extinction intensity curve would suggest that background and mass extinctions are discontinuous in magnitude. The critical bandwidth test estimates the shape of the extinction intensity curve and tests whether there is significant evidence to reject the null hypothesis that the curve is unimodal. We found statistically significant evidence ( $p=0.028)$ for the existence of a second mode in the right tail of the distribution of extinction intensities (Fig. 5B). The four intervals that make up this second mode are, from highest to lowest, the Djhulfian, Maastrichtian, Upper Ashgillian, and Guadalupian, confirming that only the end-Ordovician, end-Permian, and end-Cretaceous have extinction magnitudes that would not be expected in their local context and are not part of a continuum of extinction magnitudes.

Pattern of Temporal Change in Proportion of Genus Extinction.-Figure 4 plots the proportion of extinction in each interval arranged in temporal order. Although the numerous high values of extinction intensity in the early and mid Paleozoic and the consistently lower intensities in the Jurassic through Cenozoic produce the decline in extinction through the Phanerozoic recognized by Raup and Sepkoski (1982) and discussed by Gilinsky (1994), that decline is not monotonic. Instead, there are stratigraphically coherent intervals with generally higher and lower proportions of extinction that are highlighted in Figure 4. Indeed, when the Cambrian-Early Ordovician data are removed from consideration, it is not obvious that extinction intensities trend through time for the remainder of the Phanerozoic; rather we see low intensities during the mid Ordovician-Early Silurian (except for the late Ashgillian), Late Carboniferous-mid Permian, and Jurassic to present (except for the endCretaceous) separated by discrete intervals of high extinction intensities during the Middle Silurian-Early Carboniferous and later Permian-Triassic. In total, then, the Phanerozoic can be divided into six segments based on fluctuation in average extinction proportion per interval (Table 1, Fig. 4). Excluding the post-Arenig intervals whose extinction rates fall in a second mode in the lowess/critical bandwidth analysis described above, the six 
segments are apparent by inspection (Fig. 4) and are responsible for the pattern seen in the lowess regression in Figure 5A. Although origination does not have as sharp or distinct a set of changes from high to low proportions, the values of proportion of origination generally parallel the pattern for extinction (as will be seen in Fig. 6).

These six stratigraphically coherent segments provide another "neighborhood" context in which variation in origination and extinction may be more meaningfully judged, rather than comparing individual intervals against the full range of values that accumulated during the Phanerozoic. Although a linear regression on extinction proportions through the Phanerozoic does have a negative slope, the decline in extinction rate over time is caused by three sets of fluctuation between consistently higher and lower rates, with the negative slope of a linear regression largely determined by the anomalously high proportions of the Cambrian and Early Ordovician and the predominantly low rates since the Triassic. We make this observation to suggest that if the pattern of extinction over time is to be characterized it would be best to model it as a three-phase system, not a monotonic function (nor a two-phase system as suggested by Van Valen [1984]).

Using the stratigraphic groupings of intervals with similar extinction intensities (Table 1, Fig. 4), we see how the outlier intensities from the critical bandwidth test look within individual segments of time. We show this in both the arithmetic plot (Fig. 4A) and converting the proportions to natural logarithms (Fig. 4B). The end-Ordovician (late Ashgillian) and end-Cretaceous (Maastrichtian) points are obvious outliers, falling in intervals of generally low proportions of extinction. If the later Permian points (Guadalupian and Djhulfian) are regarded as belonging with the rest of the Permian (which could be justified because (a) their fauna is taxonomically a continuation of the earlier Permian fauna and (b) as will be noted below, the origination rates for these two intervals remain in the range of the earlier Permian) they, too, would be extreme outliers, but if they are grouped with the elevated proportions characteristic of the Triassic they are still clearly higher than any of those proportions. However, the late Frasnian (in the Late Devonian) and the late Norian/ Rhaetian (at the end of the Triassic) had extinction proportions that do not appear as outliers for the larger time segment to which each belongs, although the end-Triassic point is higher than the others in the Triassic.

Three, Not Five, Global Mass Extinctions.-We conclude there is a class of statistically distinct global mass extinctions, but that it contains only three members: the end-Ordovician, endPermian, and end-Cretaceous. These results parallel the conservative bootstrap statistical analysis of Hubbard and Gilinsky (1992), who also found only these same three unambiguous high extinction magnitudes in their analysis.

The other two traditional mass extinction intervals do not fulfill the criteria for unusual extinction effect. The late Frasnian satisfies none of the criteria: it falls within the smooth continuum of post-Arenigian extinction magnitudes, it is not one of the magnitudes in the second mode of post-Arenigian magnitudes using Silverman's critical bandwidth test, and it is not an apparent outlier among the midSilurian through Early Carboniferous extinction magnitudes. The end-Triassic is somewhat more ambiguous because it is one of the intervals in the "off track" high-end tail of the rank order distribution of post-Arenigian magnitudes. However, although it falls at the high end of the main mode in Figure 5B, the end-Triassic event does not fall in the separate mode confirmed by the Critical Bandwidth Test, nor is it distinctly different from other Triassic extinction intensities. We do not claim that the end-Frasnian and end-Triassic were innocent of pulsed extinctions, but we do infer that, by itself, extinction is insufficient to explain the strong diversity depletion at these times.

\section{The Interaction of Origination and Extinction}

Paleontologists have focused on mass extinctions as important evolutionary events for the past quarter of a century or more, but with few exceptions (e.g., Cutbill and Funnell 1967; Knoll 1989) they have paid less attention to 


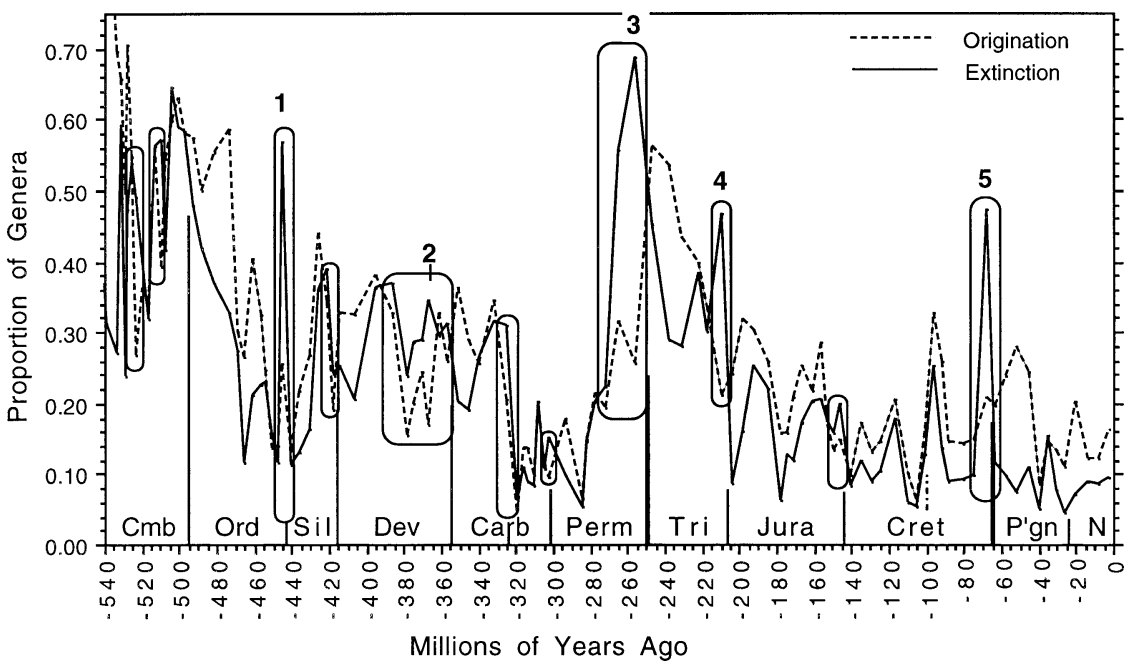

FIGURE 6. Proportions of both genus origination and extinction through the Phanerozoic. Intervals of diversity loss (extinction exceeding origination) are circled. The "big five" mass depletions are numbered.

origination, the other term in the diversity equation. In general, origination has been a focus of interest mostly for the early Paleozoic radiations (Knoll and Carroll 1999; Budd and Jensen 2000; Connolly and Miller 2001) and the recovery intervals following mass extinctions (Hart 1996).

The five intervals of diversity loss seen in Figures 1 and 2 have traditionally been regarded as mass extinctions because extinction must have exceeded origination for diversity to drop so markedly during those intervals. However, this focus on extinction ignores two conditions. One is that there is considerable genus extinction during any interval of time (over $90 \%$ of the intervals of the Phanerozoic have $8 \%$ or greater genus extinction), yet when diversity is maintained because extinction is matched by origination we are not concerned about its magnitude. Second is that origination can fluctuate, yet origination is seldom tracked. If origination should fall below typical values while extinction remained at its typical level, diversity would decrease, yet no change in extinction intensity would have occurred. How do the classic "big five" diversity depletions reflect the interaction between origination and extinction?

Interaction of Origination and Extinction in Major Diversity Depletions.-Figure 6 illustrates both origination and extinction proportions through the Phanerozoic. By definition, diversity was depleted when extinction was greater than origination, and, conversely, diversity increased when origination exceeded extinction. Diversity loss during intervals when origination rate was typical for the stratigraphic neighborhood can be ascribed to elevated extinction alone. On the other hand, diversity loss when extinction was not markedly higher than the average for its stratigraphic neighborhood must reflect suppressed origination-attrition by inadequate replacement. The intervals during which diversity decreased are circled on Figure 6 and the "big five" diversity depletions are numbered. Using the average proportion of origination and extinction for the larger intervals in which each of the "big five" diversity depletions falls (Table 1), we can calculate the proportional influence ("importance") of origination compared with extinction on the loss of diversity in each major diversity depletion (Table 2).

During the end-Ordovician, end-Permian, and end-Cretaceous diversity depletions, rates of origination were slightly to markedly greater than the average for their stratigraphic neighborhoods, whereas extinction rates were exceptionally high (Fig. 7). By this criterion, then, these three intervals can be regarded as true global mass extinctions because diversity depletion in each was driven entirely by elevated extinction. Indeed, had rates of origi- 


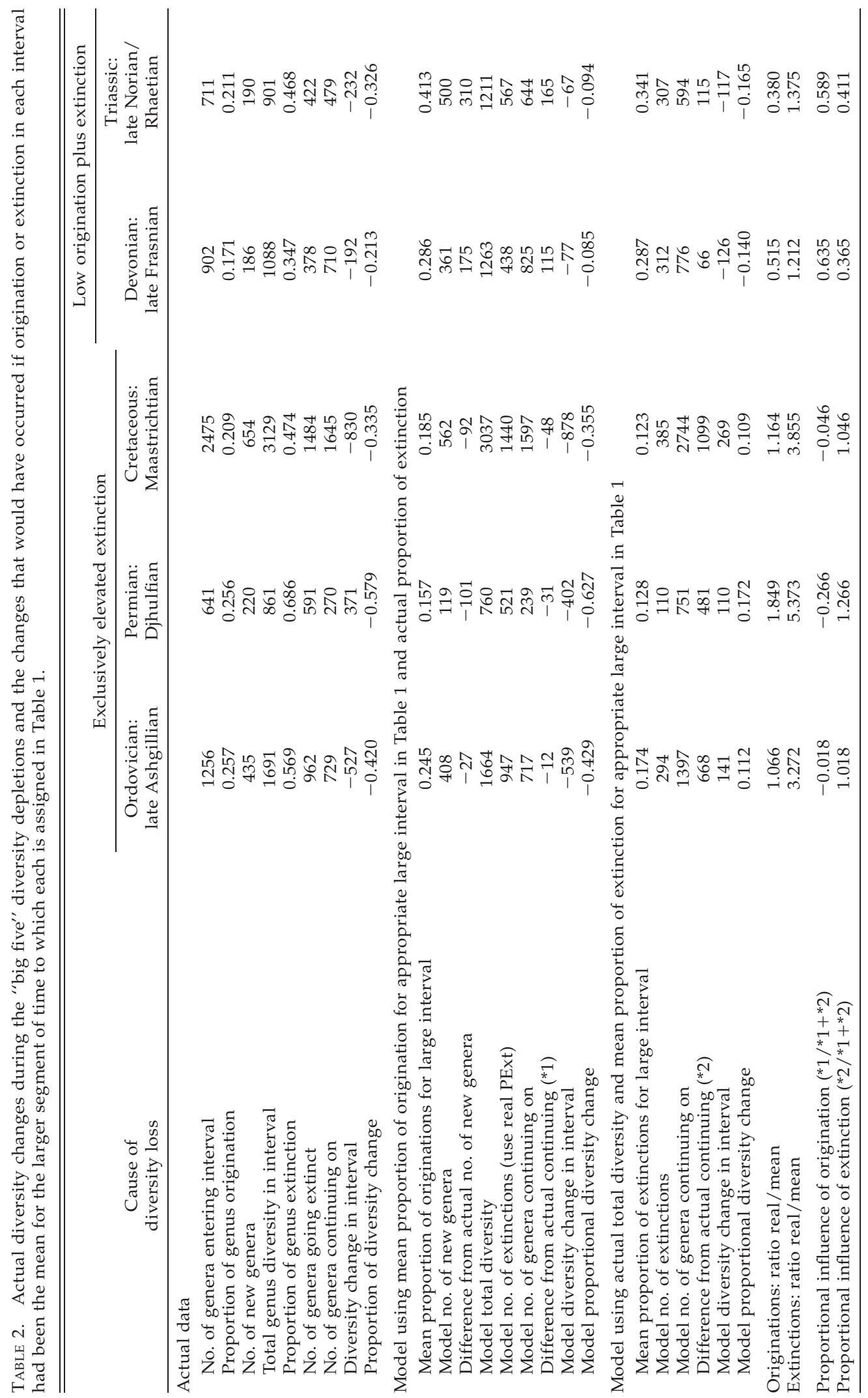



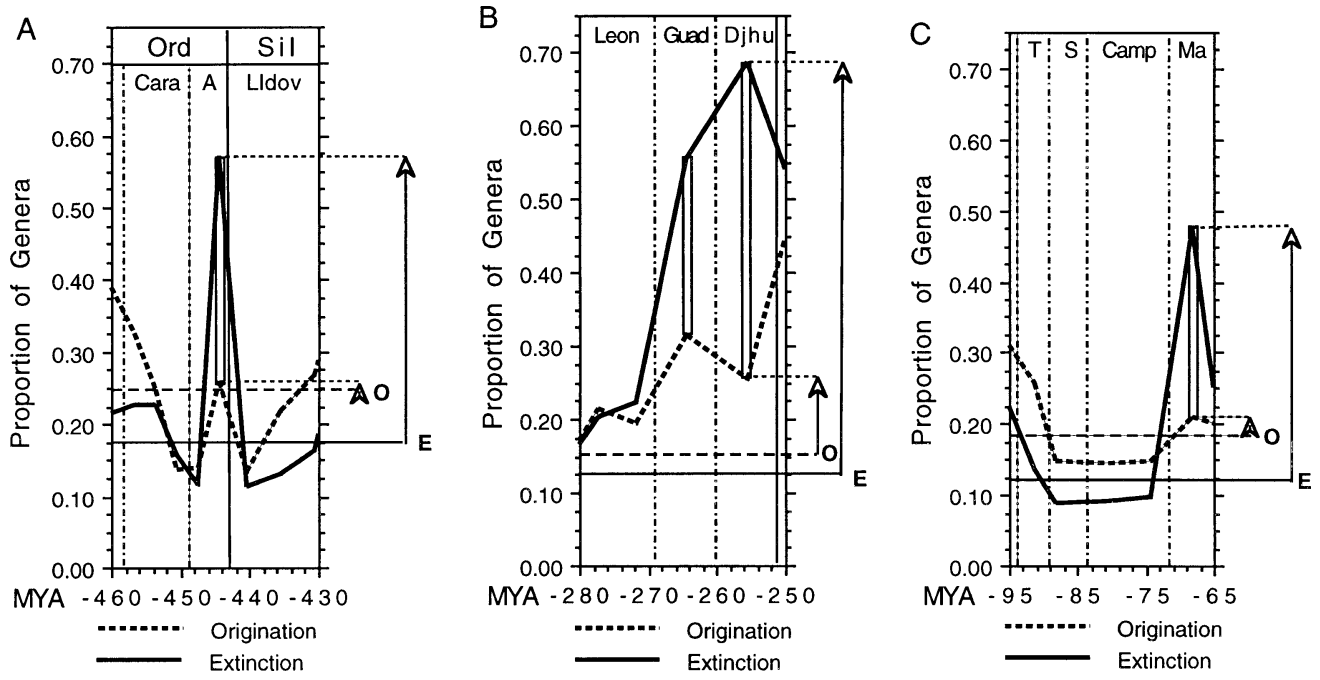

FIGURE 7. Relationship between origination and extinction for the three mass diversity depletions that are true mass extinctions. Arrow marked $\mathrm{O}$ indicates the difference between the mean origination for the larger interval to which each is assigned (Table 1), shown by a dashed horizontal line, and the actual origination in the mass depletion interval. Arrow marked $\mathrm{E}$ indicates the difference between the mean extinction for the larger interval to which each is assigned (Table 1), shown by a horizontal solid line, and the actual extinction magnitude in the mass depletion interval. Diversity loss indicated by the vertical thin box between the origination and extinction values. A, Late Ashgillian, at the end of the Ordovician. B, Djhulfian, at the end of the Permian (with marked diversity loss in the preceding Guadalupian stage, as well). C, Maastrichtian, at the end of the Cretaceous.

nation during these intervals been no more than average, diversity losses would actually have been somewhat greater than they were (Table 2). The noticeably higher-than-average proportion of origination in the Djhulfian (10\% higher than the mean for the Late Carboniferous and Permian) may reflect recovery from the diversity loss in the Guadalupian, but the other two intervals have proportions of origination only one to two-and-a-half percent higher than the average for their stratigraphic neighborhoods.

In contrast, the two remaining "big five" mass depletions-the late Frasnian and the end-Triassic - reflect a more complicated imbalance between origination and extinction (Fig. 8). During both intervals, origination was markedly lower than average for their stratigraphic neighborhoods. Although each interval registered somewhat elevated extinction, about two-thirds of the diversity loss in the late Frasnian and almost $60 \%$ in the end-Triassic can be ascribed to origination failure, not elevated extinction (Table 2). McGhee (1988) originally emphasized that low origination was a major factor in the Frasnian diversity depletion, but it is only with this paper that the role of origination failure is brought to the fore for both the Frasnian and the end-Triassic. Neither was an extinction event of the magnitude of the end-Ordovician, end-Permian, and end-Cretaceous events, yet each qualifies as one of the "big five" post-Cambrian diversity depletions because of moderately elevated extinction in concert with marked origination failure.

Other intervals that have relatively high magnitude of extinction are occasionally labeled "mass extinctions," but they do not show dramatic losses of diversity. For example, the Kacák/otomari event near the end of the Eifelian in the Middle Devonian has been associated with impact ejecta in Morocco (Ellwood et al. 2003), but the cited extinction of "as many as $40 \%$ of all marine animal genera" is actually $37 \%$ extinction for the entire $11-$ million-year-long Eifelian stage, not just the Kacák/otomari event (Sepkoski's data, cited by Ellwood et al. is only resolved to the full stage level for the Eifelian), and is nearly balanced by $33 \%$ origination, resulting in a net Eifelian diversity loss of only $4 \%$. Extinction was equal to the Eifelian level in the preceding Emsian and was actually greater in the Ludlovian of 

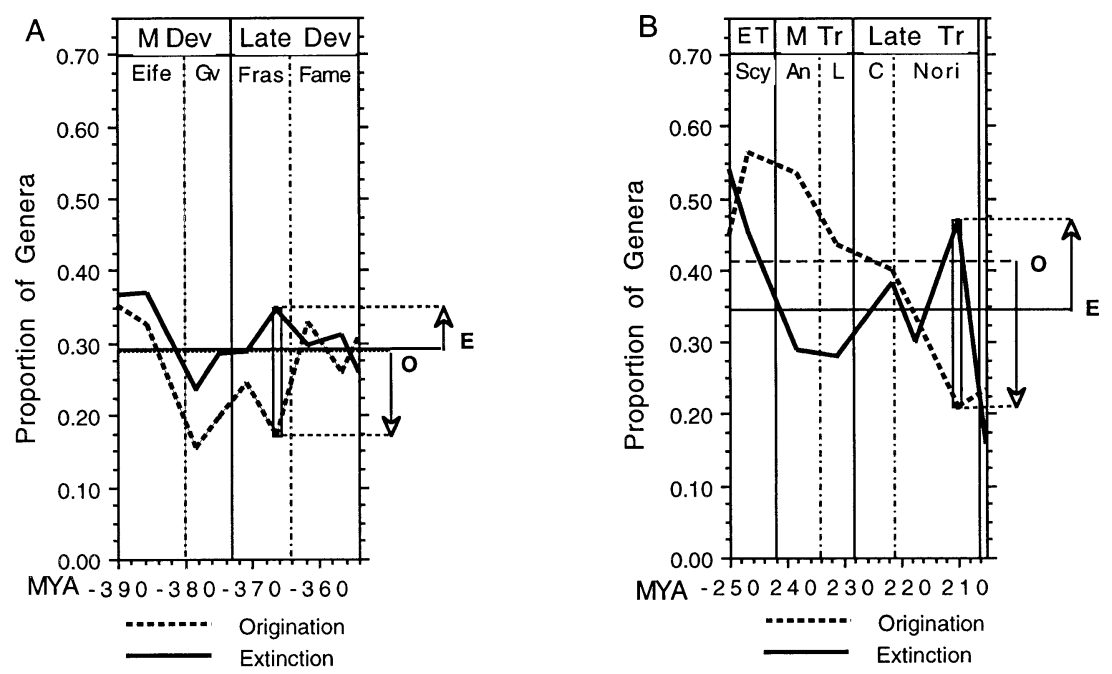

FIGURE 8. Relationship between origination and extinction for the two mass diversity depletions that are not exclusively extinction driven. Arrows as in Figure 7. Diversity loss indicated by the vertical thin box between the origination and extinction values. A, Late Frasnian, in the Late Devonian. Note that several preceding intervals also have lower origination than extinction, indicating continuous diversity loss, although a drop in origination plus a small peak of extinction concentrates more diversity loss in the late Frasnian. B, Late Norian/Rhaetian, at the end of the Triassic. In this case, proportion of origination decreased through most of the Triassic as diversity rebounded from the end-Permian mass depletion, but exceeded extinction except at the end of the Triassic, when origination was at its low point and there was a small peak of extinction.

the Silurian, but in both instances origination also nearly balanced extinction. Events that record moderate extinction over short time intervals in some regions, like the Kacák/otomari episode, deserve close attention, but they are simply not comparable to the end-Permian or end-Cretaceous devastations, nor were they associated with diversity depletions on a global scale similar to those of the late Frasnian or end-Triassic.

Mass Depletions during the Cambrian.-The Cambrian and Early Ordovician are unusual in having very low diversity and very high rates of faunal turnover. Figures 3A, 4, and 9B illustrate the preponderance of high proportional origination and extinction in this interval: $87 \%$ of the intervals in the Phanerozoic with genus origination greater than $50 \%$ and $68 \%$ of all intervals with genus extinction greater than $40 \%$ occur during the Cambrian and Early Ordovician. As noted above, it is statistically highly unlikely that the preponderance of high extinction magnitude was produced by chance alone. What makes this even more unusual is that the durations of many subdivisions during this interval are much shorter than the average through the rest of the Phanerozoic, yet taxonomic turnover is greater (as can be seen by the relative size of the turnover peaks compared with the boundary-crossing [minimum] diversity plot in Figs. 1 and 9A). Sepkoski's (1996) stratigraphic subdivisions of Cambrian time may be unrealistically small (e.g., Landing 1994), raising questions about the accuracy of his detailed correlations and calling his diversity numbers for these fine-scale intervals into question; however, combining these intervals into larger time divisions more comparable in duration to those characteristic of younger periods would result in even more pronounced turnover rates because of the short ranges of many Cambrian taxa. As an example, proportion of origination in the Middle Cambrian as a whole was 0.691 and proportion of extinction was 0.676 , whereas origination averaged 0.461 and extinction averaged 0.467 for each of the four intervals of the Middle Cambrian tabulated here. Thus, regardless of any over-optimism in the designation of stratigraphic bins used by Sepkoski, the Cambrian and Early Ordovician was an interval of unusual turnover.

Important extinctions have, of course, been recognized in the Cambrian. Signor (1992) 

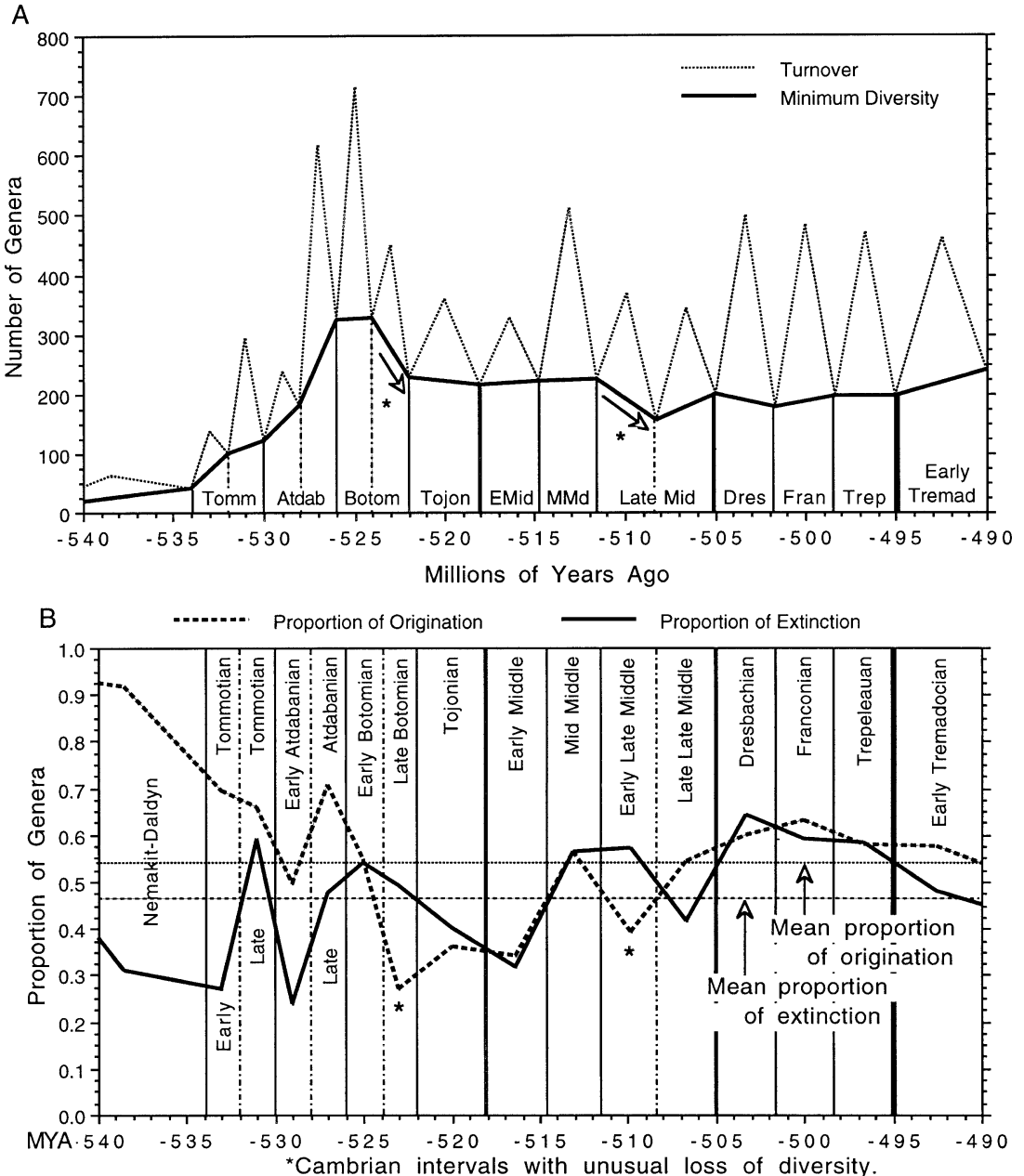

FIGURE 9. A, Genus diversity and diversity turnover through the Cambrian and Early Ordovician. Graph plotted as in Figure 1. Notice the high degree of taxonomic turnover. Arrows mark the two times of marked diversity decrease. B, Proportions of origination and extinction through the Cambrian and Early Ordovician. Both origination and extinction were generally high during the Cambrian and Early Ordovician. The two intervals of marked diversity depletion are distinguished by depression of origination, not peaks of extinction.

first pointed to the Botomian as a time of mass extinction (see also Zhuravlev and Wood 1996). Archaeocyathan diversity collapsed, and small shelly fossil diversity declined as well (although, as Porter [2003] has shown, loss of preservational opportunity clouds the picture for the latter group). Nonetheless, Sepkoski's data suggest that Botomian extinction proportions for the total fauna were actually lower than those of several other Cambrian intervals, and the marked late Botomian change for the fauna as a whole reflects a drop in origination, not an increase in extinction (Fig. 9B). The loss of diversity in the late Botomian was not because extinction proportion for arcaheo- cyathids increased, but rather because proportions of origination for archaeocyathids, problematica, hyolithids, and inarticulate brachiopods all fell to one-fifth to one-third the values they had maintained in the Atdabanian and early Botomian. Among diverse groups in the Early Cambrian, only the trilobites maintained origination rates high enough to counter attrition from the "normal" extinction proportions in the late Botomian.

The same is true for the early part of the late Middle Cambrian. Although Palmer's (1984, 1998) documentation of extinction at biomere boundaries may contribute to the high extinction magnitudes in the Middle and Late Cam- 
brian, the diversity loss of the early part of the late Middle Cambrian interval stands out mostly for its low level of genus origination (Fig. 9B). Thus, the two Cambrian intervals of diversity depletion resemble the Late Devonian and end-Triassic more closely than they do the three unambiguous global mass extinctions.

In one way, this finding is more or less inevitable. When mean rates of extinction stand at $46 \%$ per interval, driving diversity depletion by increasing extinction rate is a tall order. However, the more specific question of why archaeocyathans, trilobites, and other Cambrian dominants should have experienced declining rates of origination during these intervals has no clear answer at this time (as is also the case for the Frasnian and end-Triassic noted above). Perhaps changing Botomian ocean chemistry selected against the massive calcification that is the hallmark of archaeocyathans (e.g., Rowland and Shapiro 2002). And perhaps ocean circulation changed during the late Middle Cambrian, influencing the shelf environments that supported marine diversity. Compelling answers may come from creative interactions between paleontology and Earth system geochemistry.

\section{What about Continuity of Effect and Cause?}

Although the "big five" global mass depletions of diversity do not share continuity of magnitude it might be that they share common properties in terms of the biological effects of diversity loss. This, however, does not appear to be the case.

Knoll et al. (1996) identified a distinct selectivity in end-Permian extinction in which heavily calcified animals with low metabolic rates were devastated ( $88 \%$ genus extinction), whereas metazoans with high metabolic rates and calcareous skeletons precipitated from physiologically buffered solutions (or with skeletons made from materials other than $\mathrm{CaCO}_{3}$ ) were far less affected $(49 \%$ genus extinction), and more recent work is refining the pattern (Bambach and Knoll unpublished data). During the end-Ordovician and endCretaceous events, no selectivity of this sort occurred. Sheehan et al. (1996) documented selectivity differences in the patterns of extinction for these two events that clearly differentiate between them, and neither resembles the Permian pattern. Thus, although the end-Permian and end-Cretaceous global mass extinctions share one result-both devastated antecedent ecosystems - the patterns of the two extinctions were different and their postextinction recoveries distinct (Bambach et al. 2002). As pointed out by Droser et al. (2000), Brenchley et al. (2001), and Sheehan (2001), and confirmed quantitatively by Bambach et al. (2002), the Ordovician global mass extinction did not have a comparable effect on ecosystem structure.

As an illustration of the difference in effect of the Ordovician and Permian extinctions, a recent study of brachiopods in South China (Rong and Shen 2002) noted that there were no ordinal extinctions in the Ordovician event and that there is a "close taxonomic and ecological relationship of pre- and post-extinction brachiopod associations" (p. 25). In contrast, four orders and 20 superfamilies disappeared in the end-Permian event, and very few Triassic brachiopods link back to the Permian at the genus level. For the three unambiguous global mass extinctions, then, there are differences in the physiological selectivity of the events, the ecological impacts of the events, and the style of effect on particular taxa. Continuity of effect is simply absent.

The two other global mass depletions differ from the three global mass extinctions in numerous ways, including effect when the balance between origination and extinction is considered, but they are still not well understood. The Frasnian event is complicated. Most workers accept that at least two pulses of extinction occurred, in association with two Kellwasser black-shale horizons (see, for example, Chen and Tucker 2003). Extinction pulses are also recorded in the Middle and Late Devonian (House 1985; McGhee 1996), especially the so-called Hangenberg event at the end of the Famennian (House 1985; Simakov 1993; Wang et al. 1993). Indeed, at the stage and substage levels, marine diversity decreased almost continuously through Middle and Late Devonian time (Fig. 1). Moreover, the marine fauna underwent dramatic turn- 
over in dominant organisms (Bambach 1999). Copper (2002: p. 49) observed that reef distribution declined progressively from the Givetian through the Frasnian, and stated that there is "no catastrophic reef 'kill horizon' at the F/F boundary known anywhere in the world." Copper (2002) associated the observed decline with climatic and tectonic change. Although the causes of reduced Frasnian origination are not yet clearly known, loss of complex reef habitats could have facilitated reduced origination by eliminating a normally diverse ecosystem.

The end-Triassic event is the least well understood of the major diversity depletions. As noted above, this event was driven as much by origination failure as by extinction, in contrast to the end-Ordovician, end-Permian, and endCretaceous events. Moreover, neither glaciation nor major biotic reorganization, characteristics associated with the end-Ordovician and Late Devonian diversity depletions, is manifest in the Late Triassic (although both large plateau basalt eruptions and bolide impact have been implicated [Bice et al. 1992; Courtillot et al. 1996; Wignall 2001; Olsen et al. 2002]). Although complete and informative marine sections are still being sought (Hallam et al. 2000), there are now proposals that observed terrestrial and marine extinctions may not be synchronous (Pálfy et al. 2000) and geochemical analyses that also suggest a doublepulsed event of some sort (Hesselbo et al. 2002). In concluding a recent survey of endTriassic data, Hallam (2002: p. 133) stated, "Though the current evidence cannot decisively exclude it, the foregoing review does not favour a major T-J boundary catastrophe."

The five major mass depletions of diversity are so different in major features that it is clear they cannot share common cause. Nor did they have common effect, beyond major loss of diversity.

\section{Could It All Be Artifactual?}

Variability in the quality of the geologic record has the potential to affect observed diversity and it undoubtedly has affected some aspects of detailed interval-to-interval changes in apparent diversity (Peters and Foote 2001, 2002; Smith et al. 2001; Kier 1974 1977).
One might, therefore, question whether our conclusions reflect artifactual, rather than biological, patterns in the fossil record. Could there be defects or biases in the record that give the appearance of major diversity depletions when none actually exist?

Although we do not deny that some of the apparent diversity change in each of the "big five" diversity depletions could be accentuated by record failure, in none of these instances is it reasonable to expect that tabulated diversity change was produced entirely by failure of the rock record. For instance, Raup (1978) once estimated the amount of extinction at the end of the Permian was equivalent to an 85-million-year gap in the geologic record, something obviously precluded by radiometric ages of Permian and Triassic rocks near the Permo-Triassic boundary (Bowring et al. 1998). Also, Raup's (1982) efforts to model extinction by elimination of large areas of the Earth-originally conceived as a test of impact scenarios for extinction, but equally applicable to questions of record failure-produced surprisingly small extinctions of genera and families (mean extinction of only $13.8 \%$ of marine genera and $12 \%$ of terrestrial families) when half our planet's surface was eradicated. Record failure is simply not capable of producing apparent diversity fluctuations on the scale observed in the large global diversity depletions.

In summary, we believe that the major conclusions articulated in this paper describe real changes in the diversity of marine animals though Phanerozoic time.

\section{Conclusions}

Of 88 stage or substage intervals during the 470 million years since the Early Ordovician Arenig, only five suffered a loss of diversity greater than $13.5 \%$ of the number of marine genera that entered the interval. These five intervals - the late Ashgillian at the end of the Ordovician, the late Frasnian in the Late Devonian, the Djhulfian at the end of the Permian, the late Norian/Rhaetian at the end of the Triassic, and the Maastrichtian at the end of the Cretaceous-have been grouped as the "big five" mass extinctions, but they are better regarded as mass depletions of diversity. 
Two of the five mass depletions, the late Frasnian and the end-Triassic, resulted primarily from attrition related to reduced origination, rather than devastation from unusually elevated extinction. Both intervals occurred during times of generally high extinction, so lowered origination had severe consequences for diversity. Extinction in these two intervals was elevated above average for their stratigraphic neighborhoods, but in each case elevated extinction was responsible for only a little more than one-third of the diversity loss, leaving the remainder to be explained by reduced origination. A similar relationship between reduced origination and diversity loss is seen in two Cambrian intervals with marked loss of diversity (the late Botomian and the early part of the late Middle Cambrian).

On the other hand, diversity loss in the endOrdovician, end-Permian, and end-Cretaceous intervals resulted exclusively from elevated extinction. The extinction magnitudes of these three intervals are statistically different from the extinction magnitudes in their stratigraphic neighborhoods; they can be regarded as "true" global mass extinctions.

\section{Acknowledgments}

We thank A. I. Miller and an anonymous reviewer for many suggestions that helped to improve the manuscript. A.H.K.'s research was supported, in part, by the NASA Astrobiology Institute. S.C.W. is grateful for funding from the Swarthmore College Research Fund and the Christian R. and Mary F. Lindback Foundation.

\section{Literature Cited}

Bambach, R. K. 1983. Ecospace utilization and guilds in marine communities through the Phanerozoic. Pp. 719-746 (Chapter 15) in M. Tevesz and P. McCall, eds. Biotic interactions in recent and fossil benthic communities. Plenum, New York.

Bambach, R. K. 1985. Classes and adaptive variety: the ecology of diversification in marine faunas through the Phanerozoic. Pp. 191-253 in J. W. Valentine, ed. Phanerozoic diversity patterns: profiles in macroevolution. Princeton University Press, Princeton, N.J.

Bambach, R. K. 1999. Energetics in the global marine fauna: a connection between terrestrial diversification and change in the marine biosphere. Geobios 32:131-144.

Bambach, R. K., and N. L. Gilinsky. 1986. Perspectives on the distribution of origination and extinction during the Phanerozoic. Geological Society of America Abstracts with Programs 18:534.
Bambach, R. K., A. H. Knoll, and J. J. Sepkoski Jr. 2002. Anatomical and ecological constraints on Phanerozoic animal diversity in the marine realm. Proceedings of the National Academy of Sciences USA 99:6854-6859.

Bice, D. M., C. R. Newton, S. McCauley, P. W. Reiners, and C. A. McRoberts. 1992. Shocked quartz at the Triassic-Jurassic boundary in Italy. Science 255:443-446.

Bowring, S. A., D. H. Erwin, Y. G. Jin, M. W. Martin, K. Davidek, and W. Wang. 1998. U/Pb zircon geochronology and tempo of the end-Permian mass extinction. Science 280:1039-1045.

Brasier, M. D., and S. S. Sukhov. 1998. The falling amplitude of carbon isotopic oscillations through the lower to middle Cambrian: northern Siberia data. Canadian Journal of Earth Sciences 35:353-373.

Brenchley, P. J., J. D. Marshall, and C. J. Underwood. 2001. Do all mass extinctions represent an ecological crisis?"' Evidence from the Late Ordovician. Geological Journal 36:329-340.

Budd, G. E., and S. Jensen. 2000. A critical reappraisal of the fossil record of the bilaterian phyla. Biological Reviews 75 : 253-295.

Bush, A. M., and R. K. Bambach. In press. Did alpha diversity increase during the Phanerozoic? Lifting the veil of taphonomic, latitudinal, and environmental biases in the study of paleocommunities. Journal of Geology.

Bush, A. M., M. J. Markey, and C. R. Marshall. 2001. Estimating biodiversity in light of heterogeneous sampling intensities: the relationship between taxon-occurrence subsampling methods and alpha and beta diversity. PaleoBios 21(Suppl. to No. 2):37.

Bush, A. M., M. J. Markey, and C. R. Marshall. In press. Alpha, beta, gamma: the effects of spatially organized biodiversity on sampling-standardization. Paleobiology.

Chen, D., and M. E. Tucker. 2003. The Frasnian-Famennian mass extinction: insights from high-resolution sequence stratigraphy and cyclostratigraphy in South China. Palaeogeography, Palaeoclimatology, Palaeoecology 193:87-111.

Cleveland, W. S. 1979. Robust locally weighted regression and smoothing scatterplots. Journal of the American Statistical Association 74:829-836.

Connolly, S. R., and A. I. Miller. 2001. Global Ordovician faunal transitions in the marine benthos: proximate causes. Paleobiology 27:779-795.

Copper, P. 2002. Reef development at the Frasnian/Famennian mass extinction boundary. Palaeogeography, Palaeoclimatology, Palaeoecology 181:27-65.

Courtillot, V. J.-J. Jaeger, Z. Yang, G. Féraud, and C. Hofmann. 1996. The influence of continental flood basalts on mass extinctions: where do we stand? In G. Ryder, D. Fastovsky, and S. Gartner, eds. The Cretaceous-Tertiary event and other catastrophes in earth history. Geological Society of America Special Paper 307:513-515.

Cutbill, J. L., and B. M. Funnell, 1967. Numerical analysis of the fossil record. Pp. 791-820 in W. B. Harland, W. B., C. H. Holland, M. R. House, N. F. Hughes, A. B. Reynolds, M. J. S. Rudwick, G. E. Satterthwaite, L. B. Tarlow, and E. C. Willey, eds. The fossil record. Geological Society, London.

Droser, M. L., D. J. Bottjer, P. M. Sheehan, and G. R. McGhee. 2000. Decoupling of taxonomic and ecologic severity of Phanerozoic marine mass extinctions. Geology 28:675-678.

Ellwood, B. B., S. L. Benoist, A. El Hassani, C. Wheeler, and R. E. Crick. 2003. Impact ejecta layer from the Mid-Devonian: possible connection to global mass extinctions. Science 300: 1734-1737.

Finney, S. C., W. B. N. Berry, J. D. Cooper, R. L. Ripperdan, W. C. Sweet, S. R. Jacobson, A. Soufiane, A. Achab, and P. J. Noble. 1999. Late Ordovician mass extinction: a new perspective from stratigraphic sections in central Nevada. Geology 27: 215-218. 
Foote, M. 1988. Survivorship analysis of Cambrian and Ordovician trilobites. Paleobiology 14:258-271.

Gilinsky, N. L. 1994. Volatility and the Phanerozoic decline of background extinction intensity. Paleobiology 20:445-458.

Hallam, A. 2002. How catastrophic was the end-Triassic mass extinction? Lethaia 35:147-157.

Hallam, A., and P. B. Wignall. 1999. Mass extinctions and sealevel changes. Earth-Science Reviews 48:217-250.

Hart, M. B., ed. 1996. Biotic recovery from mass extinction events. Geological Society of London Special Publication 102.

Hesselbo, S. P., S. A. Robinson, F. Surlyk, and S. Piasecki. 2002. Terrestrial and marine extinction at the Triassic-Jurassic boundary synchronized with major carbon-cycle perturbation: a link to initiation of massive volcanism? Geology 30: 251-254.

House, M. R. 1985. Correlation of mid Paleozoic ammonoid evolutionary events with global sedimentary perturbations. Nature 313:17-22.

Hubbard, A. E., and N. L. Gilinsky. 1992. Mass extinctions as statistical phenomena: an examination of the evidence using $\chi^{2}$ tests and bootstrapping. Paleobiology 18:148-160.

Jablonski, D. J. 1986. Causes and consequences of mass extinctions: a comparative approach. Pp. 183-229 in D. K. Elliott, ed. Dynamics of extinction. Wiley, New York.

Jablonski, D. J., K. Roy, J. W. Valentine, R. M. Price, and P. S. Anderson. 2003. The impact of the Pull of the Recent on the history of marine diversity. Science 300:1133-1135.

Jackson, J. B. C., and K. G. Johnson. 2001. Measuring past biodiversity. Science 293:2401-2404.

Jin, Y.-g., Y. Wang, W. Wang, Q. H. Shang, C. Q. Cao, and D. H. Erwin. 2000. Pattern of marine mass extinction near the Permian/Triassic boundary in South China. Science 289:432-436.

Kier, P. M. 1974. Evolutionary trends and their functional significance in post-Paleozoic echinoids. Paleontological Society Memoir 5. Journal of Paleontology 48(Suppl. to No. 3).

- 1977. The poor fossil record of the regular echinoid. Paleobiology 3:168-174.

Knoll, A. H. 1989. Evolution and extinction in the marine realm: some constraints imposed by phytoplankton. Philosophical Transactions of the Royal Society of London B 325:279-290.

Knoll, A. H., R. K. Bambach, D. E. Canfield, and J. P. Grotzinger. 1996. Comparative earth history and Late Permian mass extinction. Science 273:452-457.

Knoll, A. H., and S. B. Carroll. 1999. Early animal evolution: emerging views from comparative biology and geology. Science 284:2129-2137.

Landing, E. 1994. Lower Cambrian of southeastern Newfoundland: epeirogeny and Lazarus faunas, lithofacies-biofacies links, and the myth of a global chronostratigraphy. Pp. 283309 in J. H. Lipps and P. W. Signor, eds. Origin and early evolution of the Metazoa. Plenum, New York.

Leakey, R. E., and R. Lewin. 1995. The sixth extinction: patterns of life and the future of humankind. Doubleday, New York, $271 \mathrm{p}$.

MacLeod, N., and G. Keller, eds. 1996. Cretaceous-Tertiary mass extinctions: biotic and environmental changes. Norton, New York

McGhee, George R., Jr. 1988. The Late Devonian extinction event: evidence for abrupt ecosystem collapse. Paleobiology 14:250-257.

- 1996. The Late Devonian mass extinction. Columbia University Press, New York.

- 2001. The 'multiple impacts hypothesis' for mass extinction: a comparison of the Late Devonian and the late Eocene. Palaeogeography, Palaeoclimatology, Palaeoecology 176:4758.

Newell, N. D. 1962. Paleontological gaps and geochronology. Journal of Paleontology 36:592-610.
1963. Crises in the history of life. Scientific American 208(2):77-92

1967. Revolutions in the history of life. In C. C. Albritton Jr., ed. Uniformity and simplicity. Geological Society of America Special Paper 89:63-91.

Olsen, P. E., D. V. Kent, H. D. Sues, C. Koeberl, H. Huber, A. Montanari, E. C. Rainforth, S. J. Fowell, M. J. Szajna, and B. W. Hartline. 2002. Ascent of dinosaurs linked to an iridium anomaly at the Triassic-Jurassic boundary. Science 296:13051307.

Pálfy, J., J. K. Mortensen, E. S. Carter, P. L. Smith, R. M. Friedman, and H. W. Tipper. 2000. Timing the end-Triassic mass extinction: first on land, then in the sea? Geology 28:39-42.

Palmer, A. R. 1984. The biomere problem: evolution of an idea. Journal of Paleontology 58:599-611.

1998. A proposed nomenclature for stages and series for the Cambrian of Laurentia. Canadian Journal of Earth Sciences 35:323-328.

Peters, S. E., and M. Foote. 2001. Biodiversity in the Phanerozoic: a reinterpretation. Paleobiology 27:583-601.

2002. Determinants of extinction in the fossil record. Nature 416:420-424.

Porter, S. M. 2004. Closing the "phosphatization" window: testing for the influence of taphonomic megabias on the pattern of small shelly fossil decline. Palaios 19:178-183.

Quinn, J. F. 1983. Comment on: mass extinctions in the fossil record. Science 219:1239-1240.

Raup, D. M. 1978. Cohort analysis of generic survivorship. Paleobiology 4:1-15.

- 1982. Biogeographic extinction: a feasibility test. In L. E. Silver and P. H. Schultz, eds. Geological implications of impacts of large asteroids and comets on the Earth. Geological Society of America Special Paper 190:277-281.

. 1987. Mass extinction: a commentary. Palaeontology 30: $1-13$.

1991. A kill curve for Phanerozoic marine species. Paleobiology 17:37-48.

Raup, D. M., and J. J. Sepkoski Jr. 1982. Mass extinctions in the marine fossil record. Science 215:1501-1503.

Rong, J.-y., and S.-z. Shen. 2002. Comparative analysis of the end-Permian and end-Ordovician brachiopod mass extinctions and survivals in South China. Palaeogeography, Palaeoclimatology, Palaeoecology 188:25-38.

Rowland, S. M., and R. S. Shapiro. 2002. Reef patterns and environmental influences in the Cambrian and earliest Ordovician. In W. Kiessling, E. Flügel, and J. Golonka, eds. Phanerozoic reef patterns. SEPM Special Publication. 72:95-128.

Saltzman, M. R., R. L. Ripperdan, M. D. Brasier, K. C. Lohmann, R. A. Robison, W. T. Chang, S. C. Peng, E. K. Ergaliev, and B. Runnegar. 2000. A global carbon isotope excursion (SPICE) during the Late Cambrian: relation to trilobite extinctions, organic-matter burial and sea level. Palaeogeography, Palaeoclimatology, Palaeoecology 162:211-223.

Sepkoski, J. J., Jr. 1981. A factor analytic description of the Phanerozoic marine fossil record. Paleobiology 7:36-53.

1982. A compendium of fossil marine families. Milwaukee Public Museum Contributions to Biology and Geology No. 51 .

2002. A compendium of fossil marine animal genera. Bulletins of American Paleontology No. 363

Sepkoski, J. J., Jr., R. K. Bambach, D. M. Raup, and J. W. Valentine. 1981. Phanerozoic marine diversity: a strong signal from the fossil record. Nature 293:435-437.

Sheehan, P. M. 2001. The Late Ordovician mass extinction. Annual Reviews of Earth and Planetary Science 29:331-364.

Sheehan, P. M., P. J. Coorough, and D. E. Fastovsky. 1996. Biotic selectivity during the $\mathrm{K} / \mathrm{T}$ and Late Ordovician extinction events. In G. Ryder, D. Fastovsky, and S. Gartner, eds. The 
Cretaceous-Tertiary event and other catastrophes in earth history. Geological Society of America Special Paper 307:477489.

Signor, P. W. 1992. Taxonomic diversity and faunal turnover in the Early Cambrian: did the most severe mass extinction of the Phanerozoic occur in the Botomian stage? In S. Lidgard and P. R. Crane, eds. Fifth North American Paleontological Convention, Abstracts and program. Paleontological Society Special Publication 6:272.

Signor, P. W., and J. H. Lipps. 1982. Sampling bias, gradual extinction patterns, and catastrophes in the fossil record. In L. E. Silver and P. H. Schultz, eds. Geological implications of impacts of large asteroids and comets on the Earth. Geological Society of America Special Paper 190:291-296.

Silverman, B. W. 1981. Using kernel density estimates to investigate multimodality. Journal of the Royal Statistical Society B 43:97-99.

Simakov, K. V. 1993. Biochronological aspects of the DevonianCarboniferous crisis in the regions of the former U.S.S.R. Pa- laeogeography, Palaeoclimatology, Palaeoecology 104:127137.

Smith, A. B., A. S. Gale, and N. E. A. Monks. 2001. Sea-level change and rock-record bias in the Cretaceous: a problem for extinction and biodiversity studies. Paleobiology 27:241-253.

Stanley, S. M., and X. Yang. 1994. A double mass extinction at the end of the Paleozoic era. Science 266:1340-1344.

Van Valen, L. M. 1984. A resetting of Phanerozoic community evolution. Nature 307:50-52.

Wang, K., M. Attrep, and C. J. Orth. 1993. Global iridium anomaly, mass extinction, and redox change at the Devonian-Carboniferous boundary. Geology 21:1071-1074.

Wang, S. C. 2003. On the continuity of background and mass extinction. Paleobiology 29:455-467.

Wignall, P. B. 2001. Large igneous provinces and mass extinctions. Earth-Science Reviews 53:1-33.

Wignall, P. B., and R. J. Twitchett. 1996. Oceanic anoxia and the end Permian mass extinction. Science 272:1155-1158.

Zhuravlev, A. Yu., and R. A. Wood. 1996. Anoxia as the cause of the mid-Early Cambrian (Botomian) extinction event. Geology 24:311-314. 